\title{
Leukoagglutination, Mycoplasma pneumoniae Pneumonia, and EDTA Acid Blood
}

\author{
Lökosit Agregasyonu, Mycoplasma pneumoniae Pnömonisi ve EDTA'lı Kan
}

(D) Beuy Joob ${ }^{1}$, (D) Viroj Wiwanitkit ${ }^{2}$

${ }^{1}$ Sanitation 1 Medical Academic Center, Bangkok, Thailand

${ }^{2}$ Hainan Medical University, Hainan Sheng, China; DY Patil University Faculty of Medicine, Pune, India

To the Editor,

We read the report "Peculiar Cold-Induced Leukoagglutination in Mycoplasma pneumoniae Pneumonia" with great interest [1]. Kubota et al. [1] reported an interesting patient with Mycoplasma pneumoniae pneumonia who had leukoagglutination. They noted that this is a rare condition. We agree that the patient had leukoagglutination and Mycoplasma pneumoniae pneumonia. Nevertheless, the leukoagglutination in this case may or may not have been due to Mycoplasma pneumoniae pneumonia. A common problem that might be forgotten is EDTA-induced leukoagglutination [2]. This basic laboratory interference phenomenon cannot be ruled out in the present case. As noted by Grob and Angelillo-Scherrer, EDTA-dependent leukoagglutination can be seen in healthy individuals and this is not related to Mycoplasma pneumoniae pneumonia [3].
Keywords: EDTA, Leukoagglutination, Mycoplasma

Anahtar Sözcükler: EDTA, Lökosit agregasyonu, Mikoplazma

Conflict of Interest: The authors of this paper have no conflicts of interest, including specific financial interests, relationships, and/or affiliations relevant to the subject matter or materials included.

\section{References}

1. Kubota $Y$, Hirakawa $Y$, Wakayama K, Kimura S. Peculiar cold-induced leukoagglutination in Mycoplasma pneumoniae pneumonia. Turk J Hematol 2017;34:354-355.

2. Anand $M$, Gulati $H K$, Joshi AR. Pseudoleukopenia due to ethylenediaminetetraacetate induced leukoagglutination in a case of hypovolemic shock. Indian J Crit Care Med 2012;16:113-114.

3. Grob AV, Angelillo-Scherrer A. Leukoagglutination reported as platelet clumps. Blood 2011;118:2940. 


\section{Reply to the Authors:}

\section{To the Editor,}

We thank Joob and Wiwanitkit [1] for their helpful comments regarding the cause of leukoagglutination in our case [2]. Although the underlying mechanism of in vitro leukoagglutination has not been fully clarified, leukoagglutination can be classified into two groups: (1) EDTA-dependent leukoagglutination, and (2) EDTA-independent cold-induced leukoagglutination [3,4]. As pointed out by Joob and Wiwanitkit [1], both EDTA and cold agglutinin (CA) may have been implicated in our case, although high-titer CA was detected, and numerous erythrocyte agglutinations were observed in the peripheral blood smear.

Screening for CA has shown that low-titer CAs may be found in the serum of healthy adults [5]; this may suggest the possibility that naturally occurring CA is somewhat involved in EDTA-dependent leukoagglutination in healthy subjects. Nonetheless, when leukoagglutination occurs in an EDTA-anticoagulated blood sample, additional examination of the sample using other anticoagulants could be recommended to confirm the relationship between leukoagglutination and EDTA.

\section{Best Regards \\ Yasushi Kubota, Shinya Kimura}

\section{References}

1. Joob B, Wiwanitkit V. Leukoagglutination, Mycoplasma pneumoniae pneumonia and EDTA blood. Turk J Hematol 2018;35:75.

2. Kubota Y, Hirakawa Y, Wakayama K, Kimura S. Peculiar cold-induced leukoagglutination in Mycoplasma pneumoniae pneumonia. Turk J Hematol 2017;34:354355.

3. Goyal P, Agrawal D, Kailash J, Singh S. Cold-induced pseudoneutropenia in human immunodeficiency virus infection: first case report and review of related articles. Indian J Hematol Blood Transfus 2014;30(Suppl 1):148-150.

4. Lee JH. Neutrophil aggregation on the peripheral blood smear in a patient with cold agglutinin disease. Ann Hematol 2017:96:885-886.

5. Dacie J. Auto-immune haemolytic anaemia (AIHA): cold-antibody syndromes II: immunochemistry and specificity of the antibodies; serum complement in autoimmune haemolytic anaemia. In: Dacie J (ed). The Haemolytic Anaemias. Vol. 3. London, Churchill Livingstone, 1992. 